Neuronal Excitability

\title{
Neuregulin and Dopamine D4 Receptors Contribute Independently to Depotentiation of Schaffer Collateral LTP by Temperoammonic Path Stimulation
}

\author{
(1) Yukitoshi Izumi, ${ }^{1,3,4}$ and Charles F. Zorumski ${ }^{1,2,3,4}$
}

\section{DOI:http://dx.doi.org/10.1523/ENEURO.0176-17.2017}

${ }^{1}$ Department of Psychiatry, Washington University School of Medicine, St. Louis, MO 63110, ${ }^{2}$ Department of Neuroscience, Washington University School of Medicine, St. Louis, MO 63110, ${ }^{3}$ Taylor Institute for Innovative Psychiatric Research, Washington University School of Medicine, St. Louis, MO 63110, and ${ }^{4}$ Center for Brain Research in Mood Disorders, Washington University School of Medicine, St. Louis, MO 63110

\begin{abstract}
Prior studies have found that dopamine (DA), acting at D4 receptors, and neuregulin (NRG), likely acting at ErbB4 receptors, are involved in a form of depotentiation of long-term potentiation (LTP) at Schaffer collateral (SC) synapses in the hippocampus. Furthermore, DA and NRG actions are intertwined in that NRG induces DA release. We previously found that low-frequency stimulation (LFS) of temperoammonic (TA) inputs to area CA1 also depotentiates previously established SC LTP through a complex signaling pathway involving endocannabinoids, GABA, adenosine, and mitogen-activated protein kinases (MAPKs), but not glutamate. In the present studies, we found that TA-induced SC depotentiation in hippocampal slices from Sprague-Dawley albino rats also involves activation of both D4 receptors and NRG-activated ErbB receptors, but that the roles of these two modulator systems are independent with D4 receptor antagonism failing to alter chemical depotentiation by NRG1 $\beta$. Furthermore, a selective D4 receptor agonist was unable to depotentiate SC LTP when administered alone, suggesting that D4 receptor activation is necessary but not sufficient for TA-induced SC depotentiation. Chemical depotentiation by NRG1 $\beta$ was inhibited by a Pan-ErbB antagonist and by picrotoxin (PTX), an antagonist of GABA-A receptors (GABA $A_{A}$ s), indicating that NRG likely promotes SC depotentiation via effects on GABA and interneurons. These findings have implications for understanding the role of DA and NRG in cognitive dysfunction associated with neuropsychiatric illnesses.
\end{abstract}

Key words: adenosine; endocannabinoids; ErbB; GABA; hippocampus; perforant path

\section{Significance Statement}

Low frequency activation of temperoammonic (TA) inputs to stratum lacunosum moleculare (SLM) of hippocampal area CA1 can heterosynaptically depotentiate previously established long-term potentiation (LTP) of Schaffer collateral (SC) synapses. TA-induced depotentiation involves complex signaling via endocannabinoids, GABA and adenosine. Other studies indicate that SC depotentiation can involve activation of dopamine (DA) D4 receptors following DA release mediated by neuregulin-1 (NRG1). In the present studies, we find that both D4 receptors and NRG1 contribute to TA-induced SC depotentiation but do so independently. These findings have implications for understanding cognitive defects associated with psychiatric disorders.

\section{Introduction}

Hippocampal synapses operate over a dynamic range of efficacy and are subject to both short- and long-term forms of plasticity, including long-term potentiation (LTP) and long-term depression (LTD), leading candidates as synaptic memory mechanisms (Malenka and Bear, 2004; Kandel et al., 2014, Nicoll, 2017). Because there are limits on the degree to which hippocampal synapses can po- 
tentiate or depress, there is interest in determining how synapses reset to baseline following the induction of stable synaptic plasticity. This interest is compounded by the fact that the hippocampus is a short-term, limited capacity storage system. Potential mechanisms for synaptic resetting include homeostatic plasticity, in which synapses adjust to changes in activity over time (Turrigiano, 2011), and homosynaptic resetting, in which the same synapses that are altered instruct their own resetting (Fujii et al., 1991; Bashir and Collingridge, 1994).

We have been interested in determining whether extrahippocampal inputs can instruct Schaffer collateral (SC) synapses to reset heterosynaptically following successful induction of stable LTP. We have found that low-frequency stimulation (LFS) of temperoammonic (TA) inputs to stratum lacunosum moleculare (SLM) in area CA1 can induce depotentiation (LTP-D) of SC synapses without persistently altering baseline SC transmission or the ability of SC synapses to undergo subsequent LTP after resetting (Izumi and Zorumski, 2008). TA-induced LTP-D involves complex signaling including activation of GABA-A receptors $\left(G A B A_{A} R s\right)$, cannabinoid-1 receptors (CB1Rs) and adenosine A1 receptors (A1Rs), and activation of mitogen-activated protein kinase (MAPK) signaling, including extracellular signal-related kinase 1/2 (ERK1/2) and p38 MAPK (Izumi and Zorumski, 2016).

Surprisingly, TA-induced LTP-D does not involve activation of AMPA-type glutamate receptors, NMDA receptors, metabotropic glutamate receptors, or L-type voltage-activated calcium channels (Izumi and Zorumski, $2008,2016)$. These latter observations led us to consider the role of other inputs in SLM. Besides direct glutamatergic inputs and long-range GABAergic inputs from entorhinal cortex (Basu et al., 2016), SLM receives input from neuromodulatory systems, including monoamines (Swanson and Hartman, 1975), and dopamine (DA) has previously been shown to dampen direct TA glutamatergic inputs from entorhinal cortex but not SC pathway responses (Otmakhova and Lisman, 1998). Other studies, however, have shown that activation of DA D4 receptors (D4Rs) can drive a form of SC depotentiation when activated within 30 min of LTP induction (Kwon et al., 2008). This form of LTP-D is induced by neuregulin-1 (NRG1) and involves activation of ErbB receptors, which in turn enhance DA release (Kwon et al., 2005, 2008). Similarly, homosynaptic activation of SC inputs by theta pulse stim-

Human Services National Institutes of Health National Institute of Mental Health Gant MH101874, the Taylor Family Institute, and the Bantly Foundation.

Conflict of Interest: CFZ is a member of the Scientific Advisory Board of Sage Therapeutics. Sage Therapeutics did not fund this research and was not involved in the conduct of this research. Dr. Izumi has no conflicts of interest to disclose. There are no other competing financial interests.

Acknowledgments: We thank Kazuko Izumi for technical assistance.

Correspondence should be addressed to Charles F. Zorumski, Department of Psychiatry, Washington University School of Medicine, 660 South Euclid Avenue, St. Louis MO 63110, E-mail: zorumskc@wustl.edu.

DOI:http://dx.doi.org/10.1523/ENEURO.0176-17.2017

Copyright @ 2017 Izumi and Zorumski

This is an open-access article distributed under the terms of the Creative Commons Attribution 4.0 International license, which permits unrestricted use, distribution and reproduction in any medium provided that the original work is properly attributed. ulation can reverse SC LTP via D4Rs when administered shortly after LTP induction (Kwon et al., 2008). Other studies indicate that low frequency activation of DA fibers in the hippocampus can stimulate D4Rs to dampen SC responses via activation of parvalbumin positive interneurons (Rosen et al., 2015). Based on these observations, we examined the roles of DA and NRG in TA-induced LTP-D.

\section{Materials and Methods}

\section{Hippocampal slices}

Protocols for animal use were approved by the Washington University Animal Studies Committee in accordance with national and international guidelines. Hippocampal slices were prepared from the septal (dorsal) hippocampal region of postnatal day (P)28-P32 Sprague Dawley albino rats using previously described methods (Izumi and Zorumski, 2008; Tokuda et al., 2010). Pregnant female rats were purchased from Charles River (Crl:CD(SD), RRID:RGD_734476); male offspring were raised to age 28-32 d in an approved animal care facility. On the day of experiments, rats were anesthetized with isoflurane, decapitated, and hippocampi were dissected. Isolated hippocampi were placed in ice-cold artificial CSF (ACSF) containing $124 \mathrm{mM} \mathrm{NaCl}, 5 \mathrm{mM} \mathrm{KCl}, 2 \mathrm{mM}$ $\mathrm{MgSO}_{4}, 2 \mathrm{mM} \mathrm{CaCl}, 1.25 \mathrm{mM} \mathrm{NaH} \mathrm{PO}_{4}, 22 \mathrm{mM}$ $\mathrm{NaHCO}_{3}, 10 \mathrm{mM}$ glucose, bubbled with $95 \% \mathrm{O}_{2}-5 \% \mathrm{CO}_{2}$ at $4-6^{\circ} \mathrm{C}$, and cut into $450-\mu \mathrm{m}$ slices using a rotary tissue slicer. The slices were cut to include a significant portion of entorhinal cortex to keep TA inputs to SLM in the CA1 region intact to the extent possible (Izumi and Zorumski, 2008, 2016). In the present experiments we did not monitor field potentials in SLM directly because these potentials reflect a combination of several inputs from entorhinal cortex and other regions (Basu et al., 2016; Swanson and Hartman, 1975), although prior studies indicate that repeated LFS of the TA pathway, akin to what we use in this study, produces LTD of these inputs (Dvorak-Carbone and Schuman, 1999). After preparation, slices were allowed to recover from dissection in an incubation chamber containing gassed ACSF for $1 \mathrm{hr}$ at $30^{\circ} \mathrm{C}$ before experiments.

\section{Hippocampal slice physiology}

At the time of study, slices were transferred individually to a submersion-recording chamber. Experiments were done at $30^{\circ} \mathrm{C}$ with continuous ACSF perfusion at $2 \mathrm{ml} /$ $\mathrm{min}$. Extracellular recordings were obtained from the apical dendritic layer (stratum radiatum) of the CA1 region for analysis of EPSPs using glass electrodes filled with $2 \mathrm{M}$ $\mathrm{NaCl}$ (5-10 $\mathrm{M} \Omega$ resistance).

EPSPs were evoked using 0.1 -ms constant current pulses through a bipolar stimulating electrode in the SC pathway. A second stimulating electrode was placed in the TA pathway to activate inputs to CA1 in SLM. A control input-output curve was obtained to determine stimulus intensities for subsequent studies. Responses were monitored by applying single stimuli to the SC pathway every $60 \mathrm{~s}$ at half maximal intensity. After establishing a stable baseline for at least $10 \mathrm{~min}$, SC LTP was induced 
A

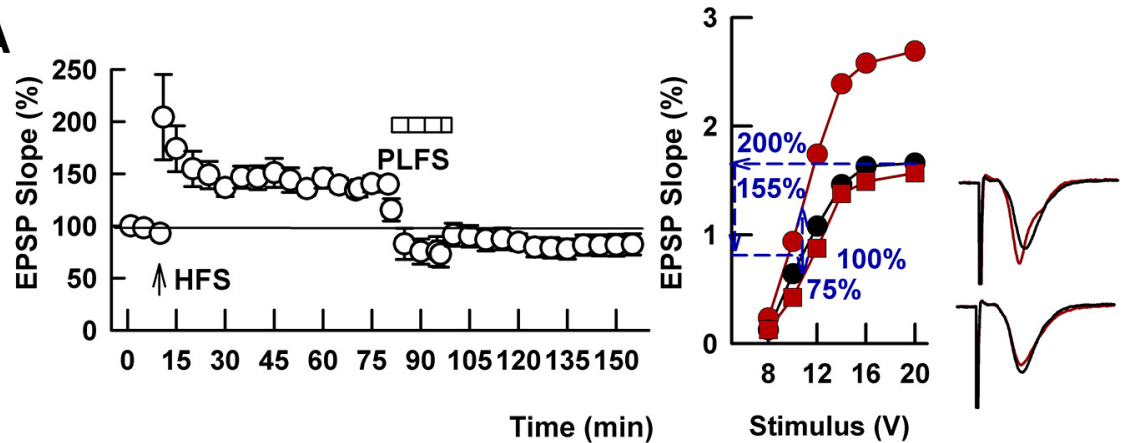

B

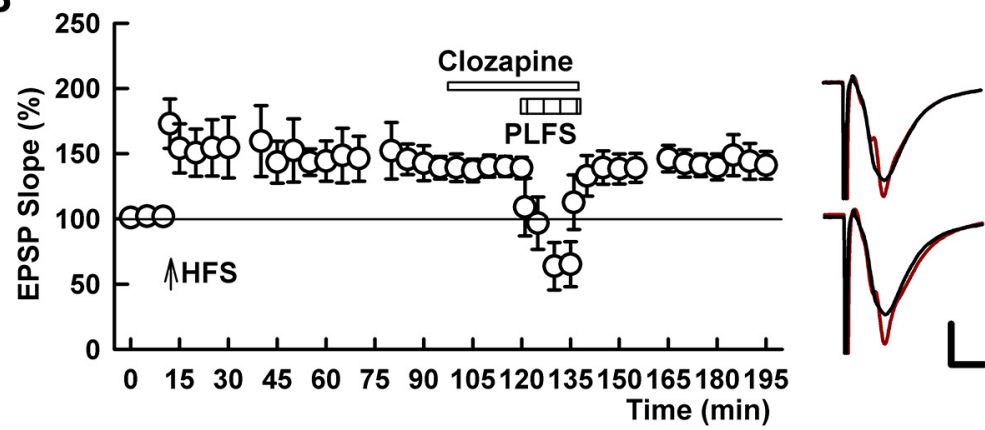

Figure 1. TA-induced LTP-D is blocked by the DA receptor antagonist, clozapine. $\boldsymbol{A}$, The left graph shows the time course of changes in EPSPs following SC HFS (arrow) and depotentiation by TA/perforant path LFS (PLFS, bar). Note that data in $\boldsymbol{A}$ include control slices done in our prior manuscript (Izumi and Zorumski, 2016) with additional slices added. The right graph in $\boldsymbol{A}$ depicts an analysis from a single slice based on changes in the $I O$ curve. Black circles are baseline IO results, while red circles depict changes 60 min after SC HFS, and red squares show reversal of LTP following PLFS. $\boldsymbol{B}$, The ability of PLFS to depotentiate SC LTP is completely blocked by $1 \mu \mathrm{M}$ clozapine (white bar). Upper traces to the right show representative EPSPs at baseline (black lines) and 60 min following SC HFS (redlines) while lower traces show baseline (black lines) compared to $60 \mathrm{~min}$ following PLFS (red lines). Calibration: $1 \mathrm{mV}, 5 \mathrm{~ms}$.

by a single $100 \mathrm{~Hz} \times 1 \mathrm{~s}$ high-frequency stimulus (HFS) using the same intensity stimulus. Input-output curves were repeated 60 min following tetanic stimulation. TA stimulation to induce SC depotentiation was administered as a $1 \mathrm{~Hz} \times 15 \mathrm{~min}$ LFS at half maximal intensity based on prior results (Izumi and Zorumski, 2008, 2016).

\section{Materials and Methods}

Chemicals and pharmacological agents were obtained from Tocris or Sigma (St. Louis MO). NRG1 $\beta$ was obtained from R\&D Systems. Concentrations of all agents used in this study (agonists and antagonists) and durations of exposure were based on published literature and, more specifically, on the lack of effect on baseline SC transmission under the conditions of our experiments. The exception to this was picrotoxin (PTX), a GABA $A_{A} R$ antagonist that induced changes in basal EPSPs even at the low concentration $(1 \mu \mathrm{M})$ used for the experiments in Figure 5. Because of the changes in basal transmission, PTX was washed on at the initiation of the recordings and included in ACSF for the duration of these experiments.

\section{Statistical analysis}

Data were collected and analyzed using PClamp software (Molecular Devices). Data in the text are expressed as mean \pm SEM. A two-tailed Student's $t$ test was used for comparisons between groups. Statistical comparisons were based on analysis of input-output curves at the $50 \%$ maximal point at baseline and sixty minutes following tetanic or $1-\mathrm{Hz}$ stimulation, with $p<0.05$ considered significant (Izumi and Zorumski, 1995). Figure $1 A$ shows an example of this type of analysis. The time course graphs in all figures display results from continuous monitoring of EPSPs using the $50 \%$ maximal stimulus from the baseline IO curve as the $100 \%$ response. Data presented in the text are derived from analysis of $I O$ curves as noted above. Analyses were done using commercial software (SigmaStat, Systat Software).

\section{Results}

In prior studies, we found that $1 \mathrm{~Hz} \times 15$ min LFS of TA (perforant path, P) inputs to area CA1 produces only a transient depression of baseline transmission of SC synapses (Izumi and Zorumski, 2008). This same TA LFS, however, persistently depotentiates previously established LTP in the SC pathway when TA stimulation is administered an hour or so following induction of stable LTP (Fig. 1A; $143.0 \pm 7.0 \%$ change in EPSP slope $60 \mathrm{~min}$ following HFS vs $80.7 \pm 8.5 \%$ change 60 min following TA LFS, $p=0.0001, N=7$ ). Because prior studies have shown that activation of D4Rs are involved in homosynaptic LTP-D and NRG1-mediated chemical depotentiation of SC LTP at short intervals following LTP induction (Kwon et al., 2008), we were interested in determining whether D4Rs also contribute to TA-induced SC LTP-D an hour or more following LTP onset. To test this, we first examined the effects of clozapine, an antipsychotic drug that inhibits D2-like DA receptors with higher affinity for 

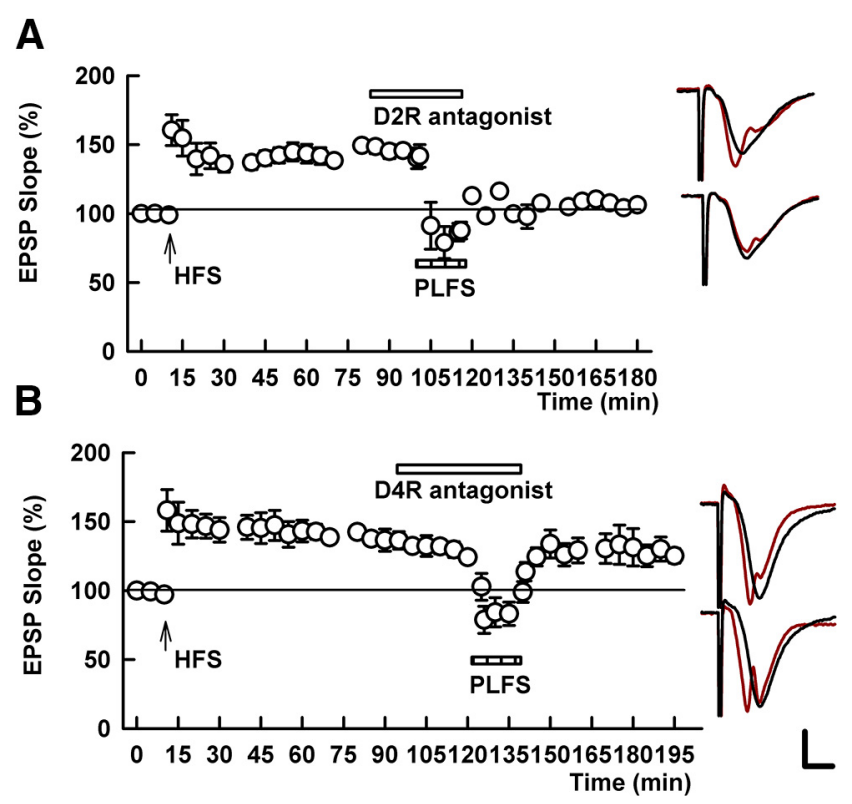

Figure 2. TA-induced LTP-D involves D4Rs. $\boldsymbol{A}$, The graph shows the inability of a selective D2R antagonist $(0.2 \mu \mathrm{M} \mathrm{L}-741,626)$ to block PLFS induced depotentiation of SC LTP. SC HFS was delivered at the arrow; PLFS was administered during the hatched bar. $\boldsymbol{B}$, In contrast, a selective D4R antagonist $(0.1 \mu \mathrm{M}$ L-745,870) completely inhibited depotentiation. Traces to the right show representative EPSPS as in Figure 1. Calibration: 1 $\mathrm{mV}, 5 \mathrm{~ms}$.

D4Rs (Sanyal and Van Tol, 1997). We found that $1 \mu \mathrm{M}$ clozapine did not alter the transient synaptic depression observed during $1-\mathrm{Hz}$ TA stimulation but completely blocked the ability of this stimulation to persistently depotentiate SC synapses (143.7 $\pm 10.5 \%$ change in EPSP slope 60 min following HFS vs $139.8 \pm 11.9 \%$ change 60 min following TA LFS, $p=0.507, N=5$; Fig. $1 B$ ).

We extended observations with clozapine using more selective antagonists against D2-type receptors. Unlike clozapine, L-741,626 (0.2 \&micro;M), a selective D2 receptor antagonist (Bowery et al., 1996), had no effect on TA-induced LTP-D $(134.7 \pm 3.8 \%$ change in EPSP slope 60 min following HFS vs $96.0 \pm 6.3 \%$ change $60 \mathrm{~min}$ following TA LFS, $p=0.0012, N=5$; Fig. $2 A$ ). In contrast, the D4R-selective antagonist, L-745,870 (Clifford and Waddington, 2000), blocked LTP-D at a concentration of 0.1 \&micro;M (134.2 $\pm 1.4 \%$ change in EPSP slope 60 min following HFS vs $123.0 \pm 4.7 \%$ change 60 min following TA LFS, $p=0.306, N=6$; Fig. $2 B$ ). These results with D4R antagonists also prompted us to examine whether D4Rs contribute to homosynaptic depotentiation in the SC collateral pathway. Consistent with prior studies,we found that $1 \mathrm{~Hz} \times 900$ pulse LFS of SC inputs reliably depotentiated SC LTP when administered an hour or more following LTP induction $(142.0 \pm 15.1 \% 60 \mathrm{~min}$ after SC HFS and $96.4 \pm 5.5 \% 60$ min after SC LFS, $N=$ $5, p=0.022$; Fig. 3A; Izumi and Zorumski, 1993). This homosynaptic SC LTP-D was completely blocked by 0.1 \&micro;M L-745,870 (155.9 $\pm 10.4 \% 60$ min after SC HFS vs $209.0 \pm 42.1 \% 60 \mathrm{~min}$ after L-745,870, $N=5, p=$ 0.312 ; Fig. 3B). Taken together, these results indicate that
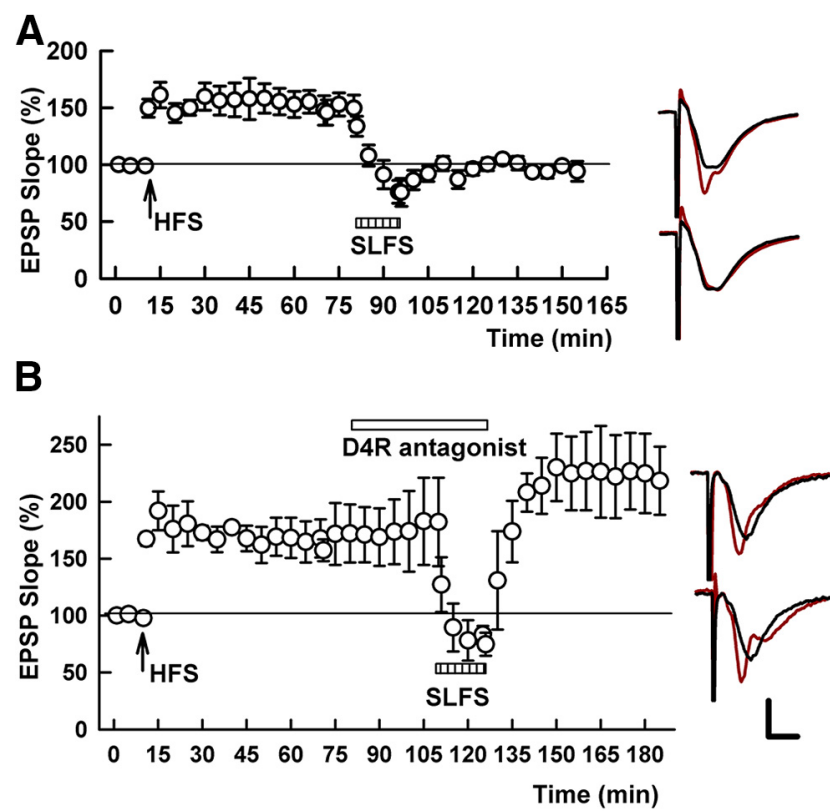

Figure 3. A D4R antagonist blocks homosynaptic SC depotentiation. $\boldsymbol{A}$, The graph shows the ability of SC LFS [SLFS $(1 \mathrm{~Hz} \times$ $15 \mathrm{~min}$ ), hatched bar] to depotentiate previously established SC LTP. SC HFS was administered at the arrow. B, The D4R antag-

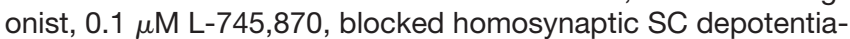
tion. For reasons that are uncertain, we observed an increase in variance of EPSPs during perfusion of the D4R antagonist in this set of studies but not in the studies shown in Figure 2. Traces to the right show representative EPSPs as in Figure 1. Calibration: $1 \mathrm{mV}, 5 \mathrm{~ms}$.

D4Rs contribute to synaptically driven SC depotentiation resulting from either heterosynaptic TA or homosynaptic SC LFS, even $1 \mathrm{~h}$ or more following LTP induction.

Earlier studies indicated that a selective D4R agonist alone was able to mimic the effects of homosynaptic SC LFS and NRG1 at early time points (30 min) after LTP induction (Kwon et al., 2008) but that NRG1 itself was ineffective when administered at later time points after LTP induction (60 min; Kwon et al., 2005).We found that the selective D4R agonist, PD-168,077 had no effect on LTP when administered alone an hour or more following SC LTP induction at either $0.2 \mu \mathrm{M}(148.1 \pm 6.7 \% 60 \mathrm{~min}$ after SC HFS vs $141.8 \pm 9.1 \% 60$ min after PD-168,077, $p=0.581, N=5$; Fig. $4 A$; Kwon et al., 2008) or 10 \&micro;M (138.2 $\pm 6.0 \% 60$ min after SC HFS vs $132.2 \pm$ $8.2 \%$ after PD-168,077, $N=5, p=0.409$ ). We did find, however, that administration of $1 \mathrm{nM} \mathrm{NRG} 1 \beta$ for $15 \mathrm{~min}$ depotentiated SC LTP when administered $60 \mathrm{~min}$ following LTP induction $(140.5 \pm 7.8 \%$ of baseline $60 \mathrm{~min}$ following HFS vs $96.2 \pm 7.8 \%$ following NRG1 $\beta, p=$ $0.002, N=6$; Fig. 4B). NRG1 $\beta$-induced depotentiation was not inhibited by the D4R antagonist (149.9 $\pm 2.8 \% 60$ min following HFS vs $91.4 \pm 5.9 \%$ after NRG1 $\beta+$ L-745,870, $p<0.0001, N=5$; Fig. $5 A$ ), indicating that NRG1 $\beta$-induced LTP-D does not require D4R activation at late time points after LTP induction.

NRG1 $\beta$-induced depotentiation was blocked by $10 \mu \mathrm{M}$ PD-158,780, a pan ErbB antagonist (133.4 $\pm 3.9 \%$ after HFS vs $128.5 \pm 2.3 \%$ after NRG1 $\beta, p=0.130, N=5$; Fig. 
A
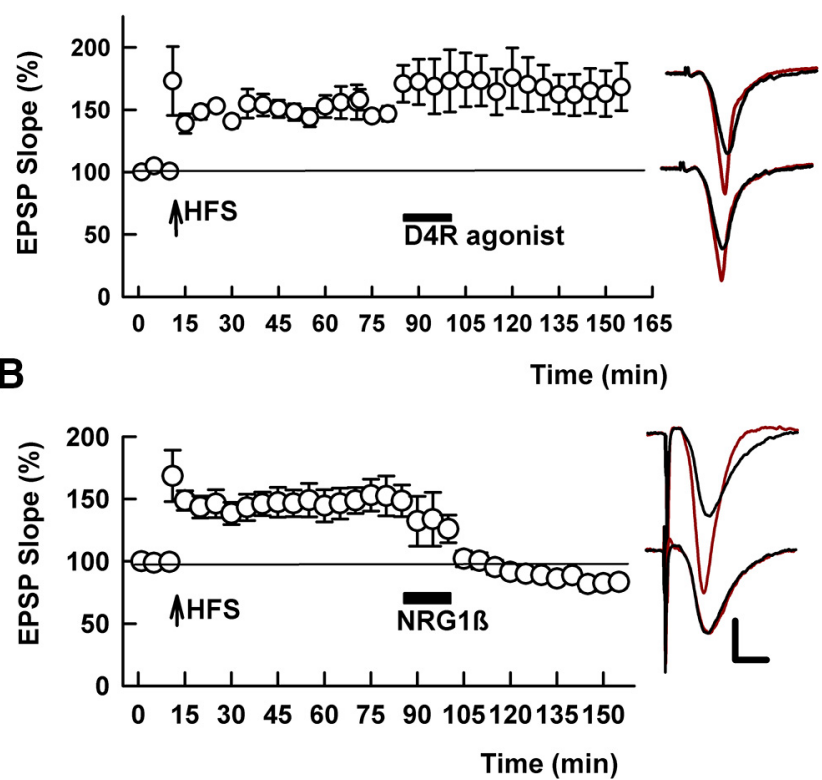

Figure 4. Exogenously administered NRG1 $\beta$, but not a D4R agonist, depotentiates SC LTP. A, A selective D4R agonist,0.2 $\mu$ M PD-168,077 (black bar), failed to depotentiate SC LTP when administered for 15 min 60 min following LTP induction. SC HFS was administered at the arrow. $\boldsymbol{B}$, In contrast to the D4R agonist, $1 \mathrm{nM}$ NRG1 $\beta$ (black bar) induced chemical depotentiation of SC LTP. Traces to the right show EPSPs as in Figure 1. Calibration: $1 \mathrm{mV}, 5 \mathrm{~ms}$.

$5 B)$ and by $0.1 \mu \mathrm{M}$ AG-1478, a more selective ErbB4 antagonist $(158.7 \pm 7.5 \%$ vs $149.0 \pm 10.5 \%, p=0.474$, $N=5$; Li et al., 2007). Because earlier studies indicated that activation of ErbB4 can stimulate GABA release from interneurons (Woo et al., 2007) and we previously found a role for GABA ${ }_{A}$ Rs in TA-induced LTP-D (Izumi and Zorumski, 2016), we examined the effects of PTX, a GABA ${ }_{A} R$ antagonist, on chemical depotentiation by NRG1 $\beta$. We found that administration of $1 \mu \mathrm{M} \mathrm{PTX}$ overcame the effects of NRG1 $\beta$ on previously established SC LTP (150.3 \pm $15.2 \%$ after HFS vs $133.9 \pm 3.7 \%$ after NRG1 $\beta+$ PTX, $p=$ $0.235, N=5$; Fig. $5 C$ ).

The ErbB antagonist, PD-158,780, also blocked TAinduced LTP-D (135.7 $\pm 11.1 \%$ of baseline 60 min following HFS vs $136.6 \pm 7.2 \%$ following TA LFS, $p=0.916$, $N=5$; Fig. $6 A$ ), but did not alter homosynaptic SC depotentiation ( $144.9 \pm 6.1 \%$ after HFS vs $97.4 \pm 5.1 \%$ after SC LFS, $N=5, p=0.0003$, Fig. $6 B$ ). These findings suggest common mechanisms in NRG-induced and TAinduced LTP-D, but not homosynaptic LTP-D.

In our prior studies of TA-induced LTP-D, we found that activation of endocannabinoid CB1Rs and adenosine A1Rs contribute to the cascade of events leading to synaptic resetting, with CB1Rs involved earlier in the pathway than A1Rs (Izumi and Zorumski, 2008). These observations prompted us to examine whether D4R blockade alters the effects of pharmacological activation of either CB1R or A1Rs on SC LTP. We found that the endocannabinoid agonist, 2-arachidonoylglycerol (2-AG, $20 \mu \mathrm{M})$ depotentiated SC LTP in the presence of the D4R
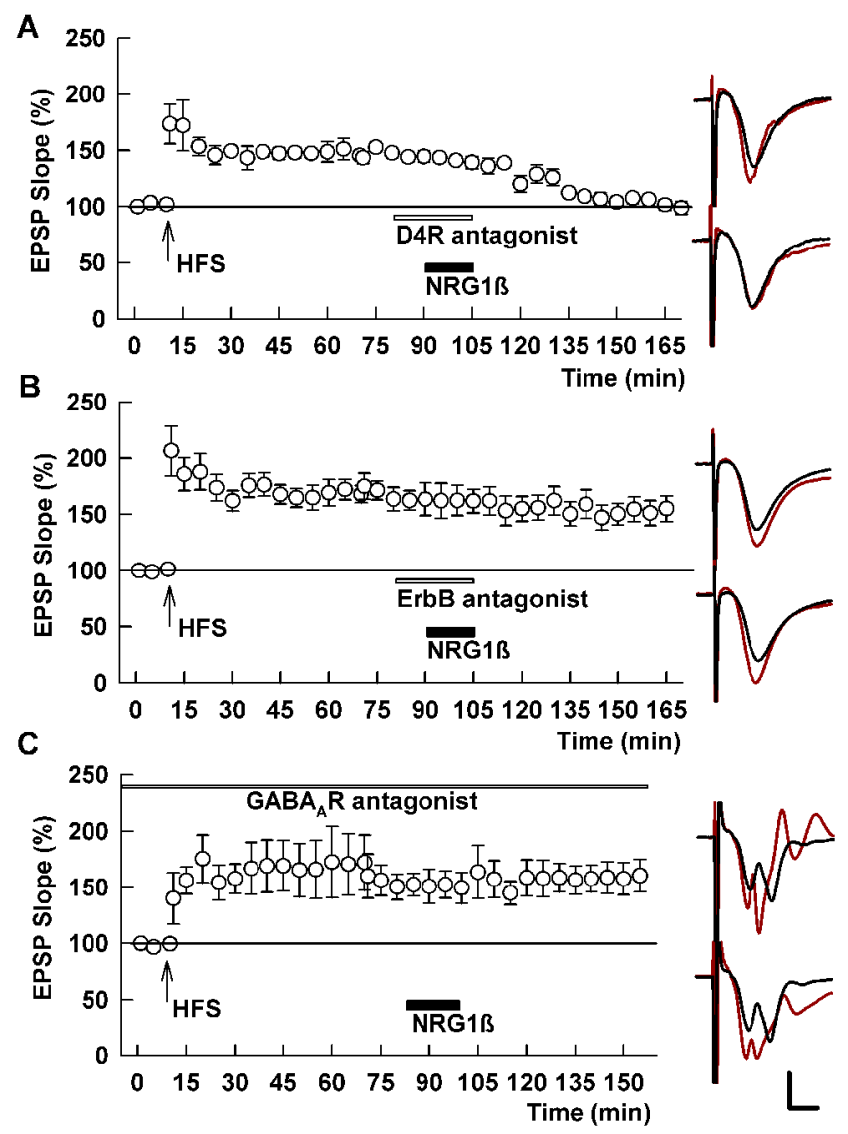

Figure 5. Depotentiation by NRG1 $\beta$ is insensitive to D4R antagonism but blocked by an ErbB antagonist and PTX. $\boldsymbol{A}$, In the

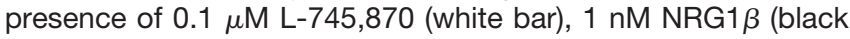
bar) induces SC depotentiation. SC HFS was administered at the arrow. $\boldsymbol{B}, \boldsymbol{C}$, In contrast to the D4R antagonist, a pan-ErbB antagonist (10 $\mu \mathrm{M}$ PD-158,780, white bar) blocks NRG1 $\beta$ induced depotentiation $(\boldsymbol{B})$, as does the $\mathrm{GABA}_{\mathrm{A}} \mathrm{R}$ antagonist, 1 $\mu \mathrm{M}$ PTX (C). Traces show representative EPSPs as in Figure 1. Calibration: $1 \mathrm{mV}, 5 \mathrm{~ms}$.

antagonist, L-745,870 (141.5 $\pm 7.9 \%$ of baseline $60 \mathrm{~min}$ after HFS vs $105.6 \pm 3.7 \%$ after $2 \mathrm{AG}, p=0.0034, N=5$; Fig. 7A). Similarly, in the presence of 1 \&micro;M clozapine, $10 \mathrm{nM}$ cyclopentyladenosine (CPA), an A1R agonist, readily reversed SC LTP $(136.7 \pm 4.2 \%$ of baseline $60 \mathrm{~min}$ after HFS vs $82.3 \pm 5.4 \%$ after CPA, $p=0.0004, N=5$; Fig. $7 B$ ). Interestingly and unlike the D4R antagonist, the ErbB antagonist, PD-158,780, completely blocked 2AGmediated depotentiation $(156.4 \pm 16.9 \%$ of baseline 60 min following HFS vs $159.5 \pm 13.4 \% 60$ min after $2 A G$, $p=0.542, N=5$; Fig. $7 C$ ). Taken together with our prior studies (Izumi and Zorumski, 2008, 2016), these results indicate that both $\mathrm{CB} 1 \mathrm{R}$ and $\mathrm{A} 1 \mathrm{R}$ activation likely occur downstream of $\mathrm{D} 4 \mathrm{R}$ activation and that ErbB receptor activation occurs downstream of CB1Rs but upstream of A1Rs.

\section{Discussion}

Hebbian plasticity in the hippocampus is thought to play a key role in learning and memory (Kandel et al., 2014; Nicoll, 2017), but has the limitation that this type of use-dependent synaptic change is saturable unless there 
A
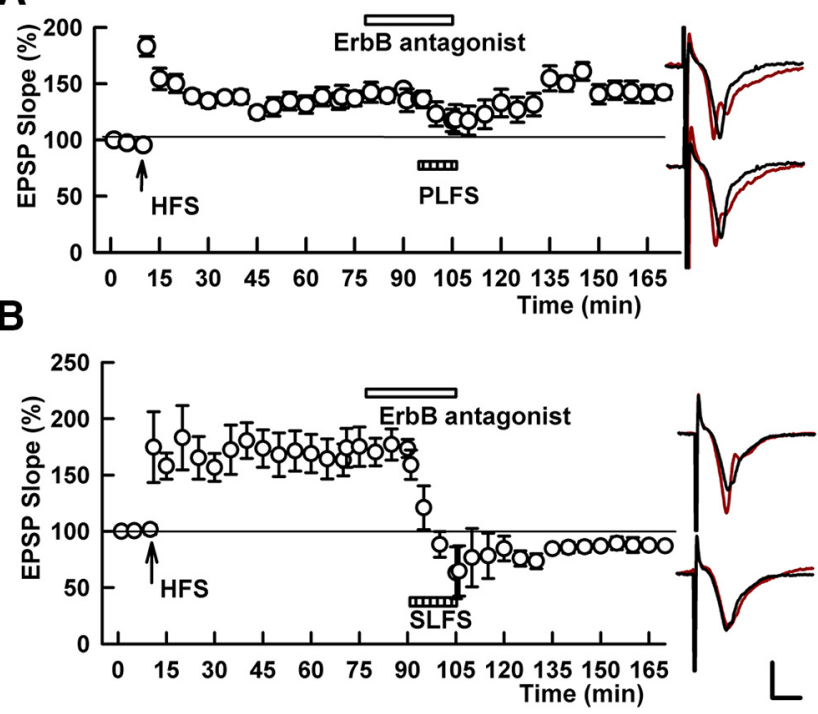

Figure 6. An ErbB antagonist blocks TA-induced, but not homosynaptic SC depotentiation. $\boldsymbol{A}$, In the presence of $10 \mu \mathrm{M}$ PD-158,780, TA stimulation (PLFS, hatched bar) fails to induce persistent SC depotentiation. SC HFS was administered at the arrow. B, In contrast, the ErbB antagonist fails to block depotentiation induced by homosynaptic SC LFS (SLFS, hatched bar). Traces show representative EPSPs as in Figure 1. Calibration: $1 \mathrm{mV}, 5 \mathrm{~ms}$.

are mechanisms by which synapses can be reset for future plasticity and learning (Turrigiano, 2011). Hence, there has been interest in understanding mechanisms by which synapses depotentiate following LTP induction, including homeostatic changes, and forms of homosynaptic and heterosynaptic depotentiation. We previously found that LFS of direct TA (perforant path) inputs to area CA1 can depotentiate previously established SC pathway LTP, without having persisting effects either on baseline transmission or the ability of subsequent stimulation to induce LTP or LTD at SC synapses (Izumi and Zorumski, 2008). TA-induced SC depotentiation involves complex signaling mechanisms including $\mathrm{GABA}_{A} R s, \mathrm{CB} 1 \mathrm{Rs}$ and adenosine $A 1 R s$ along with activation of two MAP kinases, ERK1/2 and p38 MAPK (Izumi and Zorumski, 2008, 2016).Surprisingly, this form of synaptic plasticity does not appear to involve activation of glutamate receptors (Izumi and Zorumski, 2016). In the present work, we provide evidence that TA-induced SC depotentiationinvolves activation of D4 type DA receptors and ErbB signaling.

Prior studies indicate that DA plays a key role in modulating hippocampal function, including long-term forms of synaptic plasticity (Furth et al., 2013). Intriguingly, DA innervation of area CA1, particularly afferents arising from DA cell bodies in the ventral tegmental area to SLM, is relatively sparse, with an absence of DA transporters but significant expression of DA receptors in SLM (Kwon et al., 2008; Smith and Greene, 2012; Kempadoo et al., 2016). Other work indicates that adrenergic terminals in the hippocampus can release DA and that afferents from the locus coeruleus may be critical for providing DA signals to the CA1 region (Smith and Greene, 2012; Kempa-
A

B
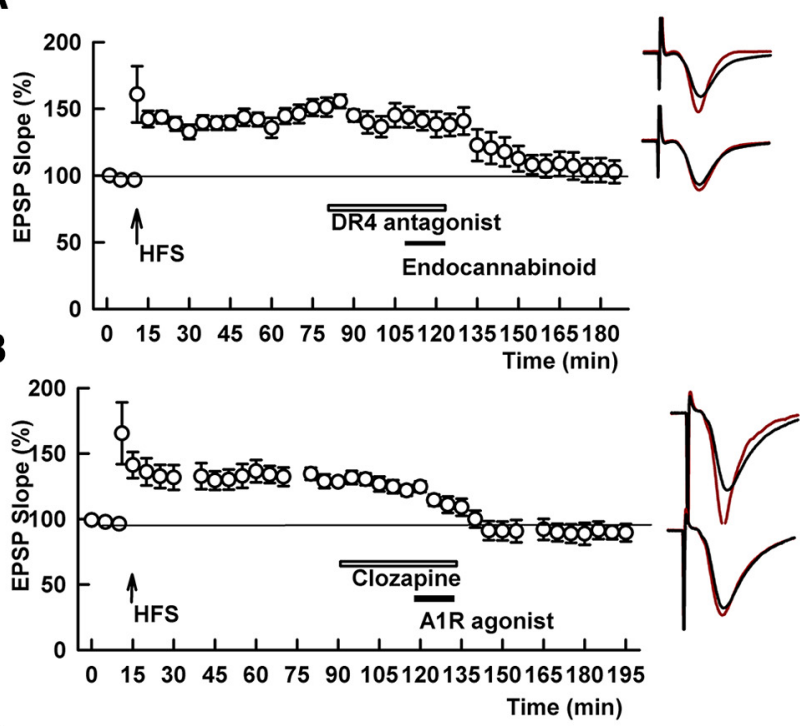

C
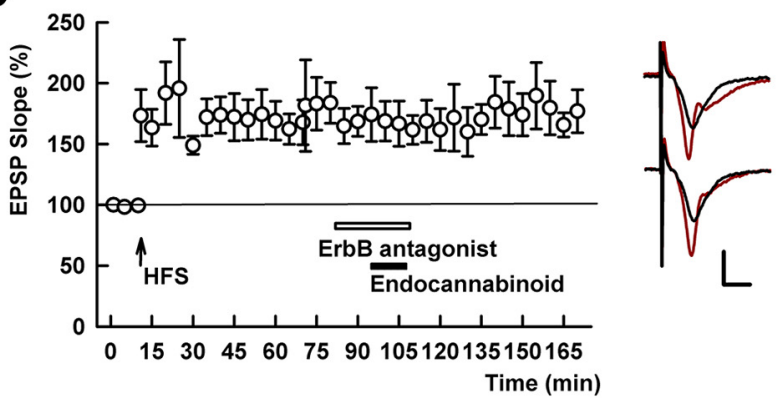

Figure 7. D4R antagonism does not block chemical depotentiation by CB1R or adenosine A1R activation, but ErbB antagonism blocks the effects of a CB1R agonist. $A$, In the presence of the D4R antagonist, L-745,870 (white bar), the endocannabinoid, 20 $\mu \mathrm{M}$ 2-AG (black bar), reversed SC LTP. SC HFS was administered at the arrow. $\boldsymbol{B}$, Similarly, clozapine, a DAR antagonist with selectivity for D4Rs (white bar), failed to block depotentiation by $10 \mathrm{nM}$ CPA, a selective A1R agonist (black bar). $\boldsymbol{C}$, The effects of 2AG on SC STP were blocked by the ErbB antagonist, PD158,780. Traces show representative EPSPs as in Figure 1. Calibration: $1 \mathrm{mV}, 5 \mathrm{~ms}$.

doo et al., 2016). Additionally, norepinephrine can directly activate D4Rs providing another way that the adrenergic system can stimulate DAreceptors to modulate CA1 function (Root et al., 2015; Sánchez-Soto et al., 2016). If norepinephrine is the key monoamine transmitter driving TA-induced SC depotentiation, our present results indicate that its effects on SC LTP involve D4Rs. We previously found that exogenous norepinephrine, acting at adrenergic receptors, prevented rather than promoted homosynaptic SC depotentiation (Katsuki et al., 1997), indicating that norepinephrine alone does not mimic the effects of TA stimulation.

Buonanno and colleagues previously demonstrated a role for D4Rs in a form of chemical depotentiation of SC LTP induced by NRG1 $\beta$ and involving activation of ErbB receptors (Kwon et al., 2005, 2008). They also found that NRG1 $\beta$ promoted release of DA in the CA1 region, indicating that the effects of NRG and DA are intertwined. 
D4Rs also contributed to homosynaptic SC depotentiation following theta pulse stimulation administered shortlyafter LTP was induced (Kwon et al., 2008). These forms of depotentiation, particularly NRG1 $\beta$-induced LTP-D, were observed within 30 min of LTP induction, but not 50 or more min after stable LTP had been established. Prior studies have found that LTP is more readily reversed early $(<30 \mathrm{~min})$ after induction rather than later after induction (an hour or more; Izumi and Zorumski, 1993; Barr et al., 1995; Stäubli and Chun, 1996; Kwon et al., 2005, 2008). Several factors may contribute to the stability of LTP over time and the ease with which LTP can be reversed, including the stimuli used to induce LTP (e.g., single vs multiple HFS), the conditions under which LTP was induced (e.g., ionic conditions, age of animals; Huang et al., 1996; Huang and Kandel, 2005) and the type and duration of stimulation used to induce depotentiation (briefer HFS trains vs LFS of varying durations; Fujii et al., 1991; Izumi and Zorumski, 1993; Bashir and Collingridge,1994; Wagner and Alger, 1995; Kwon et al., 2005). In our studies we used a single $100 \mathrm{~Hz} \times 1 \mathrm{~s}$ HFS to induce LTP that remained stable for over an hour in P30 rat hippocampal slices and reversed this LTP using $15 \mathrm{~min} 1-\mathrm{Hz}$ LFS; the LFS used for depotentiation was selected based on a standard LFS that has been used to induce homosynaptic LTD (Dudek and Bear, 1992) or LTP-D in the SC pathway (Izumi and Zorumski, 1993). These differences in stimulation paradigms may contribute to the fact we were able to reverse SC LTP an hour or more after induction.

In the hippocampus, ErbB4 receptors are a predominant NRG receptor (Li et al., 2007) and are expressed on GABAergic interneurons (Vullhorst et al., 2009; Neddens and Buonanno, 2010; Bean et al., 2014). NRG1 $\beta$ disinhibits interneurons via ErbB4 and promotes release of GABA (Woo et al.2007). Consistent with this, we found that NRG1 $\beta$-induced SC depotentiation was blocked by a $\mathrm{GABA}_{\mathrm{A}} \mathrm{R}$ antagonist, suggesting that NRG1-induced GABA release may be critical for this form of synaptic resetting. The effects of NRG1 $\beta$ on stable LTP were not reversed by a D4R antagonist, suggesting that mechanisms contributing to early and later LTP reversal by NRG1 $\beta$ and D4R activation likely differ. Other evidence indicates that D4Rs, like ErbB4, are expressed on some interneurons (Mrzljak et al., 1996), and recent work has shown that low DA release evokes feedforward inhibition in CA1 that is mediated by D4Rs on parvalbumin (PV)positive interneurons (Rosen et al., 2015). Despite the fact that TA-induced LTP-D is blocked by a D4R antagonist, we found that a D4R agonist alone failed to depotentiate SC LTP when administered $1 \mathrm{~h}$ after LTP induction, although NRG1 $\beta$ was effective. At present we do not know which interneurons contribute to TA-induced SC depotentiation, but note that several types of interneurons have dendrites in or extending to SLM, including PV+ interneurons (axo-axonic and some basket cells), cholecystokininpositive interneurons and neurogliaform cells (Klausberger et al., 2003; Klausberger and Somogyi, 2008; Klausberger, 2009; Overstreet-Wadiche and McBain, 2015) along with longer-range GABAergic inputs from entorhinal cortex to SLM (Basu et al., 2016).

\section{PP (TA)-induced SC Depotentiation}

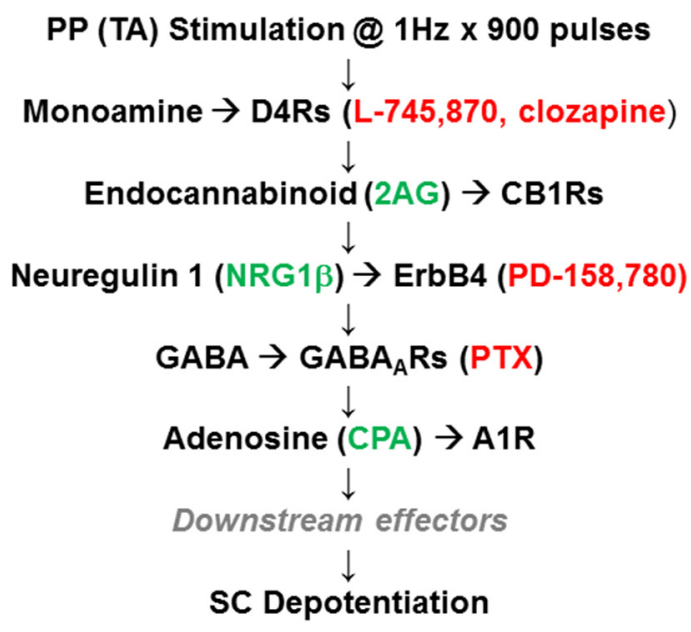

Figure 8. The diagram depicts a current scheme for TA-induced SC LTP-D based on prior studies (Izumi and Zorumski, 2008, 2016) and the present results. Agents that promote chemical depotentiation are shown in green while agents that inhibit TAinduced SC depotentiation are shown in red.

Based on the effects of selective agonists and antagonists, we have proposed a scheme for TA-induced SC depotentiation in which activation of ERK1/2, diacylglycerol lipase, and endocannabinoid synthesis are involved relatively early in the cascade, with activation of $\mathrm{GABA}_{A} \mathrm{Rs}$, p38 MAPK, and A1Rs participating as more downstream effectors (Izumi and Zorumski, 2016). Our present results indicate that D4Rs act more proximally in the depotentiation scheme than endocannabinoids, NRG1 or adenosine. D4Rs can also stimulate ERK1/2 (Bitner et al., 2006; Oak et al., 2001), which we have found is involved relatively early in the depotentiation scheme (Fig. 8). Consistent with Kwon et al. (2005, 2008), we also found that a D4R agonist alone was not capable of inducing depotentiation when administered an hour or more after LTP had been established. These findings suggest that D4R activation is necessary but not sufficient to induce TA-mediated synaptic resetting, and that D4Rs and ErbB receptors act independently in the cascade. Based on experiments to date, adenosine is the most distal signal in the cascade yet identified. We have tested some messengers linked to A1R-induced LTD (Brust et al., 2006; Chen et al., 2014) in our prior work and found a role for p38 MAPK (Izumi and Zorumski, 2016). However, in our experiments p38 MAPK appeared to act upstream of A1Rs and did not block the effects of chemical depotentiation by CPA.

The involvement of D4Rsand NRG1 $\beta$ in TA-induced SC depotentiation provides a possible link to the role of the DA and NRG systems in cognitive defects associated with psychiatric illnesses such as schizophrenia, major depression, substance use disorders, and attention deficit hyperactivity disorder (Buonanno, 2010; Shamir et al., 2012; Penzes et al., 2013). D4Rs in the hippocampus modulate gamma oscillations that are important in atten- 
tion and information processing (Andersson et al., 2012). Similarly, by altering the ability of synapses to reset following LTP, changes in DA and NRG function could be important in driving changes in hippocampal input-output relationships observed in animal models of psychiatric illnesses (Airan et al., 2007), and perhaps in the ability to learn and remember new information. The net effects of changes in DA and NRG modulation, even within the CA1 region, likely depend on input-specific actions and the subtypes of receptors that are stimulated, as well as on the state of glutamate synapses at the time of modulator release. In Drosophila, DA plays complex roles in memory and is required for both learning and forgetting (Berry et al., 2012); furthermore, sleep has been found to promote memory in Drosophila by impairing DA-driven forgetting (Berry et al., 2015). From the perspective of D4Rs, hyperdopaminergic tone would be expected to promote reversal of hippocampal and cortical LTP, perhaps leading to defects in longer-term memory storage (Xu et al., 2009), while lower DA tone could result in more persisting LTP in the CA1 region, perhaps dampening the ability of synapses to reset for future potentiation and learning. Thus efforts to modulate D4Rs and NRG signaling could have unique effects in a range of neuropsychiatric illnesses depending on the state of glutamate synapses, perhaps leading to novel ways to dampen the cognitive dysfunction that underlies illness-related disability.

\section{References}

Airan RD, Meltzer LA, Roy M, Gong Y, Chen H, Deisseroth K (2007) High-speed imaging reveals neurophysiological links to behavior in an animal model of depression. Science 317:819-823. CrossRef

Andersson RH, Johnston A, Herman PA, Winzer-Serhan UH, Karavanova I, Vullhorst D, Fisahn A, Buonanno A (2012) Neuregulin and dopamine modulation of hippocampal gamma oscillations is dependent on dopamine D4 receptors. Proc Natl Acad Sci USA 109:13118-13123. CrossRef

Barr DS, Lambert NA, Hoyt KL, Moore SD, Wilson WA (1995) Induction and reversal of long-term potentiation by low- and highintensity theta pattern stimulation. J Neurosci 15:5402-5410. Medline

Bashir ZI, Collingridge GL (1994) An investigation of depotentiation of long-term potentiation in the CA1 region of the hippocampus. Exp Brain Res 100:437-443. Medline

Basu J, Zaremba JD, Cheung SK, Hitti FL, Zemelman BV, Losonczy A, Siegelbaum SA (2016) Gating of hippocampal activity, plasticity, and memory by entorhinal cortex long-range inhibition. Science 351:aaa5694. CrossRef Medline

Bean JC, Lin TW, Sathyamurthy A, Liu F, Yin D-M, Xiong W-C, Mei $L$ (2014) Genetic labeling reveals novel cellular targets of schizophrenia susceptibility gene: distribution of GABA and non-GABA ErbB4-positive cells in adult mouse brain. J Neurosci 34:1354913566. CrossRef

Berry JA, Cervantes-Sandoval I, Chakraborty M, Davis RL (2015) Sleep facilitates memory by blocking dopamine neuron-mediated forgetting. Cell 161:1656-1667. CrossRef Medline

Berry JA, Cervantes-Sandoval I, Nicholas EP, Davis RL (2012) Dopamine is required for learning and forgetting in Drosophila. Neuron 74:530-542. CrossRef Medline

Bitner RS, Nikkel AL, Otte S, Martino B, Barlow EH, Bhatia P, Stewart AO, Brioni JD, Decker MW, Moreland RB (2006) Dopamine D4 receptor signaling in the rat paraventricular hypothalamic nucleus: evidence of natural coupling involving immediate early gene induction and mitogen activated protein kinase phosphorylation. Neuropharmacol 50:521-531. CrossRef Medline
Bowery BJ, Razzaque Z, Emms F, Patel S, Freedman S, Bristow L, Kulagowski J, Seabrook GR (1996) Antagonism of the effects of (+)-PD128907 on midbrain dopamine neurons in rat brain slices by a selective D2 receptor antagonist L-741,626. Br J Pharmacol 119:1491-1497. Medline

Buonanno A (2010) The neuregulin signaling pathway and schizophrenia: from genes to synapses and neural circuits. Brain Res Bull 83:122-131. CrossRef Medline

Brust TB, Cayabyab FS, Zhou N, MacVicar BA (2006) p38 Mitogenactivated protein kinase contributes to adenosine $A 1$ receptormediated synaptic depression in area CA1 of the rat hippocampus. J Neurosci 26:12427-12438. CrossRef

Chen Z, Xiong C, Pancyr C, Stockwell J, Walz W, Cayabyab FS (2014) Prolonged adenosine A1 receptor activation in hypoxia and pial vessel disruption focal cortical ischemia facilitates clathrinmediated AMPA receptor endocytosis and long-lasting synaptic inhibition in rat hippocampal CA3-CA1 synapses: differential regulation of GluA2 and GluA1 subunits by p38 MAPK and JNK. J Neurosci 34:9621-9643. CrossRef Medline

Clifford JJ, Waddington JL (2000) Topographically based search for an ethogram among a series of novel D4 dopamine receptor agonists and antagonists. Neuropsychopharmacol 22:538-544. CrossRef

Dudek SM, Bear MF (1992) Homosynaptic long-term depression in area CA1 of hippocampus and effects of N-methyl-D-aspartate receptor blockade. Proc Natl Acad Sci USA 89:4363-4367. CrossRef

Dvorak-Carbone H, Schuman E (1999) Long-term depression of temperoammonic-CA1 hippocampal synaptic transmission. J Neurophysiol 81:1036-1044. Medline

Fujii S, Saito K, Miyakawa H, Ito KI, Kato H (1991) Reversal of long-term potentiation (depotentiation) induced by tetanus stimulation of the input to CA1 neurons of guinea pig hippocampal slices. Brain Res 555:112-122. CrossRef

Furth KE, Mastwal S, Wang KH, Buonanno A, Vullhorst D (2013) Dopamine, cognitive function and gamma oscillations: role of D4 receptors. Front Cell Neurosci 7:1-19. CrossRef

Huang YY, Kandel ER (2005) Theta frequency stimulation induces a local form of late phase LTP in the CA1 region of the hippocampus. Learn Mem 12:587-593. CrossRef

Huang YY, Nguyen PV, Abel T, Kandel ER (1996) Long-lasting forms of synaptic potentiation in the mammalian hippocampus. Learn Mem 3:74-85. Medline

Izumi Y, Zorumski CF (1993) Nitric oxide and long-term synaptic depression in the rat hippocampus. Neuro Report 4:1131-1134. Medline

Izumi Y, Zorumski CF (1995) Developmental changes in long-term potentiation in CA1 of rat hippocampal slices. Synapse 20:19-23. CrossRef

Izumi Y, Zorumski CF (2008) Direct cortical inputs erase LTP at Schaffer collateral synapses. J Neurosci 28:9557-9563. CrossRef Medline

Izumi Y, Zorumski CF (2016) GABA and endocannabinoids mediate depotentiation of Schaffer collateral synapses induced by stimulation of temperoammonic inputs. PLoS One 11:e0149034. CrossRef Medline

Kandel ER, Dudai Y, Mayford MR (2014) The molecular and systems biology of memory. Cell 157:163-186. CrossRef Medline

Katsuki H, Izumi Y, Zorumski CF (1997) Noradrenergic regulation of synaptic plasticity in the hippocampal CA1 region. J Neurophysiol 77:3013-3020. Medline

Kempadoo KA, Mosharov EV, Choi SJ, Sulzer D, Kandel ER (2016) Dopamine release from the locus coeruleus to the dorsal hippocampus promotes spatial learning and memory. Proc Natl Acad Sci USA 113:14835-14840. CrossRef Medline

Klausberger T (2009) GABAergic interneurons targeting dendrites of pyramidal cells in the CA1 area of the hippocampus. Eur $\mathrm{J}$ Neurosci 30:947-957. CrossRef Medline

Klausberger T, Magill PJ, Márton LF, Roberts JD, Cobden PM, Buzsáki G, Somogyi P (2003) Brain-state- and cell-type-specific 
firing of hippocampal interneurons in vivo. Nature 421:844-848. CrossRef Medline

Klausberger T, Somogyi P (2008) Neuronal diversity and temporal dynamics: the unity of hippocampal circuit operations. Science 321:53-57. CrossRef Medline

Kwon OB, Longart M, Vullhorst D, Hoffman DA, Buonanno A (2005) Neuregulin-1 reverses long-term potentiation at CA1 hippocampal synapses. J Neurosci 25:9378-9383. CrossRef Medline

Kwon OB, Paredes D, Gonzalez CM, Neddens J, Hernandez L, Vullhorst D, Buonanno A (2008) Neuregulin-1 regulates LTP at CA1 hippocampal synapses through activation of dopamine D4 receptors. Proc Natl Acad Sci USA 105:15587-15592. CrossRef Medline

Li B, Woo RS, Malinow R (2007) The neuregulin-1 receptor erbB4 controls glutamatergic synapse maturation and plasticity. Neuron 54:583-597. CrossRef

Malenka RC, Bear MF (2004) LTP and LTD: an embarrassment of riches. Neuron 44:5-21. CrossRef Medline

Mrzljak L, Bergson C, Pappy M, Huff R, Levenson R, Goldman-Rakic PS (1996) Localization of dopamine D4 receptors in GABAergic neurons of the primate brain. Nature 381:245-248. CrossRef Medline

Neddens J, Buonanno A (2010) Selective populations of hippocampal interneurons express ErbB4 and their number and distribution is altered in ErbB4 knockout mice. Hippocampus 20:724-744. CrossRef Medline

Nicoll RA (2017) A brief history of long-term potentiation. Neuron 93:281-290. CrossRef Medline

Oak JN, Lavine N, Van Tol HH (2001) Dopamine D(4) and D(2L) receptor stimulation of the mitogen-activated protein kinase pathway is dependent on trans-activation of the platelet-derived growth factor receptor. Mol Pharmacol 60:92-103.

Otmakhova NA, Lisman JE (1998) Dopamine selectively inhibits the direct cortical pathway to the CA1 hippocampal region. J Neursci 19:1437-1445.

Overstreet-Wadiche L, McBain CJ (2015) Neurogliaform cells in cortical circuits. Nat Rev Neurosci 16:458-468. CrossRef Medline

Penzes P, Buonanno A, Passafaro M, Sala C, Sweet RA (2013) Developmental vulnerability of synapses and circuits associated with neuropsychiatric disorders. J Neurochem 126:165-182. CrossRef Medline

Root DH, Hoffman AF, Good CH, Zhang S, Gigante E, Lupica CR, Morales M (2015) Norepinephrine activates dopamine D4 receptors in the rat lateral habenula. J Neurosci 35:3460-3469. CrossRef Medline

Rosen ZB, Cheung S, Siegelbaum SA (2015) Midbrain dopamine neurons bidirectionally regulate CA3-CA1 synaptic drive. Nature Neurosci 18:1763-1771. CrossRef Medline
Sánchez-Soto M, Bonifazi A, Cai NS, Ellenberger MP, Newman AH, Ferré S, Yano H (2016) Evidence for noncanonical neurotransmitter activation: norepinephrine as a dopamine D2-like receptor agonist. Mol Pharmacol 89:457-466. CrossRef Medline

Sanyal S, Van Tol HH (1997) Review the role of dopamine D4 receptors in schizophrenia and antipsychotic action. J Psych Res 31:219-232. Medline

Shamir A, Kwon O-B, Karavanova I, Vullhorst D, Leiva-Salcedo E, Janssen MJ, Buonanno A (2012) The importance of the NRG-1/ ErbB4 pathway for synaptic plasticity and behaviors associated with psychiatric disorders. J Neursosci 32:2988-2997. CrossRef Medline

Smith CC, Greene RW (2012) CNS dopamine transmission mediated by noradrenergic innervation. J Neurosci 32:6072-6080. CrossRef Medline

Stäubli U, Chun D (1996) Factors regulating the reversibility of longterm potentiation. J Neurosci 16:853-860. Medline

Swanson LW, Hartman BK (1975) The central adrenergic system: an immunofluorescence study of the location of cell bodies and their efferent connections in the rat utilizing dopamine-betahydroxylase as a marker. J Comp Neur 163:467-506. CrossRef

Tokuda K, O’Dell KA, Izumi Y, Zorumski CF (2010) Midazolam inhibits hippocampal long-term potentiation and learning through dual central and peripheral benzodiazepine receptor activation and neurosteroidogenesis. J Neurosci 30:16788-16795. CrossRef Medline

Turrigiano G (2011) Too many cooks? Intrinsic and synaptic homeostatic mechanisms in cortical circuit refinement. Annu Rev Neurosci 34:89-103. CrossRef Medline

Vullhorst D, Neddens J, Karavanova I, Tricoire L, Petralia RS, McBain CJ, Buonanno A (2009) Selective expression of ErbB4 in interneurons, but not pyramidal cells, of the rodent hippocampus. J Neurosci 29:12255-12264. CrossRef Medline

Wagner JJ, Alger BE (1995) GABAergic and developmental influences on homosynaptic LTD and depotentiation in rat hippocampus. J Neurosci 15:1577-1586. Medline

Woo R-S, Li X-M, Tao Y, Carpenter-Hyland E, Huang YZ, Weber J, Neiswender H, Dong Y-P, Wu J, Gassmann M, Lai C, Xiong W-C, Gao T-M, Mei L (2007) Neuregulin-1 enhances depolarizationinduced GABA release. Neuron 54:599-610. CrossRef

Xu T-X, Sotnikova TD, Liang C, Zhang J, Jung JU, Spealman RD, Gainetdinov RR, Yao W-D (2009) Hyperdopaminergic tone erodes prefrontal long-term potential via a D2 receptoroperated protein phosphatase gate. J Neurosci 29:1408614099. CrossRef 